\section{Untimely death of Soviet virologist after hostile letters}

\section{London}

DR VIKTOR Zhdanov, a pioneer of Soviet AIDS research, who died of a cerebral haemorrhage last July, may have had his end hastened by a campaign of hostile anonymous letters, according to Sovetskaya Kultura, a thrice-weekly newspaper published under the auspices of the Central Committee of the Communist Party of the Soviet Union. During the past three years, the paper says, a spate of such denunciations, addressed to various highaccused Zhdanov of various academic malpractices, including the use of ghostwriters and "finding his wife a snug place" in his own institute.

Although these charges were eventually dismissed and although, in the words of one of Zhdanov's friends "it is impossible to associate his death with the anonymous letters in a juridicial sense", the paper suggests that the harassment must have precipitated his collapse. It claims that its own investigations show that the attacks were written by disgruntled scientists who found it difficult to get on with Zhdanov. separate AIDS institute. level Party and administrative bodies,

Zhanov was a forceful figure. Director of the Moscow Institute of Virology since 1961 , he was one of the first Soviet scientists to take up the challenge of molecular biology and was the first to address the public on the problem of AIDS.

On the other hand, some of his own published results were, to say the least, controversial. A western colleague who visited him a few days before his death reported him to be in apparently excellent spirits, although he seemed to be concerned about his current project, an attempt to obtain money to establish a

Sovetskaya Kultura seems, in part, to be using Zhdanov's death to highlight a loophole in Soviet law. Several years ago, the Soviet criminal code was amended to make anonymous libel an indictable offence, but there is as yet no provision in the law which would forbid officials who receive anonymous letters from considering and acting on them. Such an additional amendment, the newspaper considers should be introduced as soon as possible.

Vera Rich

\section{Plates rattle in Los Angeles earthquake}

\section{Washington}

THE earthquake of magnitude 6.1 on the Richter scale which hit Los Angeles at 7.42 a.m. on 1 October, causing six deaths and widespread urban damage, and the aftershock on 4 October of magnitude 5.5, were unusual but not extraordinary events. Tremors of similar magnitude struck the metropolitan area in 1933 and 1971. What was unusual, according to Dr Lucy Jones of the California Institute of Technology, was that the preceding 11 months had seen no events larger than magnitude 4.0, the longest such interval recorded. Caltech's seismology instruments in Pasadena, nine miles north of the epicentre, were put out of action by the earthquake.

For the local population, the greatest significance of the quake was that it was on the Whittier fault, which is unconnected with the San Andreas fault about $\mathbf{3 0}$ miles away. Seismologists therefore see no portent in Thursday's event of any imminent catastrophe from the better-known fault system. For geologists, says Jones, the greatest scientific interest may derive from the earthquake's location at the end of the Whittier fault. Its dynamics could

The dotted circle shows the approximate area of damage of last week's earthquake. Large black circle, 8.0 on the Richter scale; smaller circles, 6.0-6.9 on the Richter scale. The black circle marked 1987 is the epicentre of the recent earthquake. Scale bar, 20 miles. shed light on how a fault line terminates.

Although many windows were broken and some freeway sections were cracked, damage was generally minor. The citizens of Los Angeles, well-drilled in earthquake procedure, gathered in the streets while the danger passed, and Mayor Tom Bradley was evidently pleased that the city coped efficiently.

David Lindley

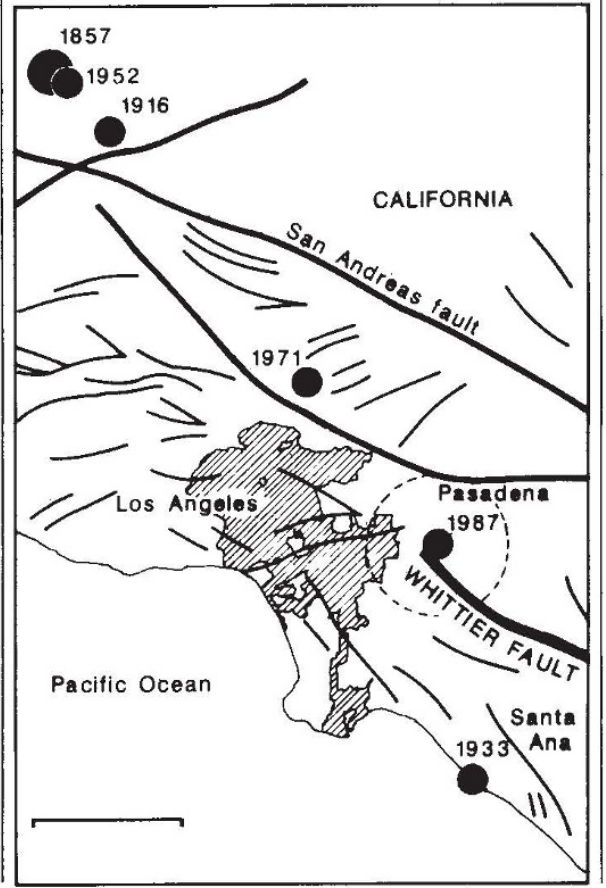

\section{Clinical research on the move}

\section{London}

BRITAIN's Medical Research Council (MRC) has declared itself in favour of abandoning its Clinical Research Centre for a physical and intellectual merger with the Royal Postgraduate Medical School. If and when that can be achieved, the council further intends to transfer its National Institute of Medical Research to form part of the new centre.

The council's decision, taken last week, is the latest shot in a battle that has raged since early last year, when the merger was first adopted as the solution to a "crisis in clinical research". Since then, the decision as to the site of the proposed centre has bounced between the council, a committee under Sir Robin Nicholson and a firm of management accountants. The council has now plumped for the Royal Postgraduate Medical School site, in the London district of Hammersmith, subject to some conditions that suggest the battle is not yet won.

As well as the obvious condition that sufficient land adjacent to the Hammersmith site can be acquired to make the merger possible, the council is not yet satisfied that the governance of the proposed centre, which would probably become a constituent school of the University of London, would allow the council sufficient financial and strategic control.

A further condition is that certain areas of research, notably psychiatry, infectious diseases and clinical molecular genetics, must be properly represented in the centre. These are seen as essential areas of clinical research for any national centre. Their extensive development at the Clinical Research Centre has been possible because of its physical association with a general community hospital. The Royal Postgraduate Medical School, by contrast, is not strong in these specialities and it would be both difficult and contrary to the current plans of the relevant health authorities to change that situation. "I do not see how anyone could decide on the Hammersmith site with expansion in mind", says Sir Christopher Booth, who will retire as director of the Clinical Research Centre by 1989 , "because the health authorities have said there can be no expansion here". Yet another committee has been set to solve the problem.

The next step in the negotiations is for the Nicholson committee, on which all relevant parties are represented at a senior level, to make a definitive recommendation on siting. Even assuming it supports the Hammersmith site, it is estimated that it will take at least five years for the merger to be completed at a cost of more than $£ 80$ million. Peter Newmark 